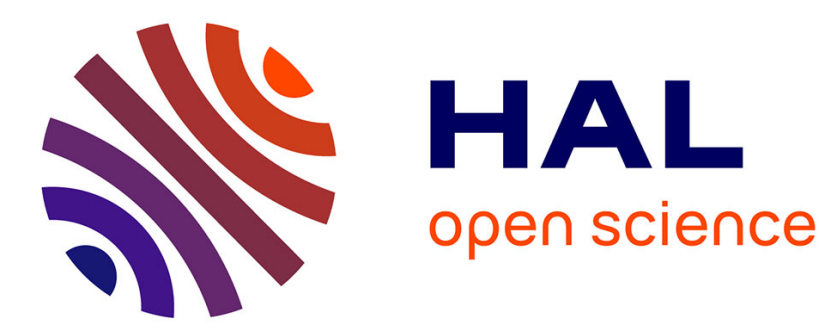

\title{
Hybrid high-energy high-power pulsewidth-tunable picosecond source
}

Julien Pouysegur, Florent Guichard, Yoann Zaouter, Marc Hanna, Frédéric

Druon, Clemens Hönninger, Eric Mottay, Patrick Georges

\section{To cite this version:}

Julien Pouysegur, Florent Guichard, Yoann Zaouter, Marc Hanna, Frédéric Druon, et al.. Hybrid highenergy high-power pulsewidth-tunable picosecond source. Optics Letters, 2015, 40 (22), pp.5184-5187. 10.1364/OL.40.005184 . hal-01306667

\section{HAL Id: hal-01306667}

\section{https://hal-iogs.archives-ouvertes.fr/hal-01306667}

Submitted on 25 Apr 2016

HAL is a multi-disciplinary open access archive for the deposit and dissemination of scientific research documents, whether they are published or not. The documents may come from teaching and research institutions in France or abroad, or from public or private research centers.
L'archive ouverte pluridisciplinaire HAL, est destinée au dépôt et à la diffusion de documents scientifiques de niveau recherche, publiés ou non, émanant des établissements d'enseignement et de recherche français ou étrangers, des laboratoires publics ou privés. 


\title{
Hybrid high-energy high-power pulsewidth- tunable picosecond source
}

\author{
Julien Pouysegur, ${ }^{1,2, *}$ Florent Guichard, ${ }^{1,2}$ Yoann Zaouter,${ }^{1}$ Marc Hanna, ${ }^{2}$ Frédéric Druon, ${ }^{2}$ \\ Clemens Hönninger, ${ }^{1}$ Eric Mottay, ${ }^{1}$ and Patrick Georges ${ }^{2}$ \\ ${ }^{1}$ Amplitude Systèmes, 11 Avenue de Canteranne, Cité de la Photonique, 33600 Pessac, France \\ 'Laboratoire Charles Fabry, UMR 8501, Institut d'Optique, CNRS, Univ Paris Sud 11, 2 Av. A. Fresnel, 91127 Palaiseau, France \\ ${ }^{*}$ Corresponding author: julien.pouysegur@institutoptique.fr
}

\begin{abstract}
A hybrid ytterbium-doped fiber-bulk laser source allowing the generation of $3 \mathrm{ps}, 350 \mu \mathrm{J}, 116 \mathrm{MW}$ peak power Fourier transform-limited pulses at $50 \mathrm{kHz}$ repetition rate and $1030 \mathrm{~nm}$ wavelength is described. Pulse duration tunability is provided by an adjustable spectral compression-based seeder system. Energy scaling capabilities of the architecture by use of the divided-pulse amplification method are investigated. This source provides a robust, compact, and versatile solution for applications such as RF photocathode guns, $x$ - and $\gamma$-ray generation by inverse Compton scattering, and optical parametric chirped-pulse amplification pumping.
\end{abstract}

High-repetition rate, high-energy picosecond sources are required for the development of secondary sources, such as photocathode RF guns, $x$ - and $\gamma$-ray generation using inverse Compton scattering, and optical parametric chirped-pulse amplification (OPCPA) systems. These applications have noteworthy operating points in the 1-20 ps laser pulse duration regime, and often specify a narrow spectral bandwidth. For electron gun and OPCPA applications [1-3], the narrow spectral width is dictated by the need to use the second, third, or fourth harmonic of the laser initial frequency. Nonlinear frequency conversion is made considerably simpler if the initial pulses are close to Fourier transform-limited (FTL), relaxing constraints on the spectral acceptance of the process. X-ray sources using inverse Compton scattering use resonant cavity enhancement of the laser radiation, for which a narrower spectrum allows much larger field enhancement factors $[4,5]$.

A widely adopted solution to amplify picosecond pulses relies on the use of Nd-doped materials, such as $\mathrm{Nd}: \mathrm{YVO}_{4}$. Such amplifiers benefit from a large achievable gain and moderate setup complexity [6-8]. By cascading several amplification stages or using multipass geometries, energies of several hundreds of microjoules can be obtained in 10 ps pulses $[9,10]$. However, the narrow spectral emission cross section of neodymium does not allow the generation of pulse durations below 10 ps [10,11]. Moreover, average power scaling of these systems is limited by the relatively large quantum defect.

In contrast, systems based on ytterbium-doped materials allow average power scaling due to the low quantum defect of the pumping scheme, and broader spectral emission cross sections permit the generation of much shorter pulses, well in the femtosecond-picosecond regime $[12,13]$. For example, a system delivering $1.3 \mathrm{~mJ}, 7$ ps pulses at $800 \mathrm{kHz}$ repetition rate, corresponding to an average power beyond $1 \mathrm{~kW}$, has been demonstrated [13], although in a relatively complex setup.

Ytterbium-doped fibers amplifiers (YDFAs) can also be used to amplify picosecond pulses, with the associated benefits of large gain, beam quality, and average power scaling, but the small core dimensions restrict the pulse energy below $100 \mu \mathrm{J}[14,15]$. The chirped-pulse amplification technique (CPA) that is routinely used to scale the energy of femtosecond systems cannot be easily implemented for FTL picosecond pulses due to the narrow spectral bandwidth. However, an equivalent attractive alternative, denoted as divided-pulse amplification (DPA), has recently been used in this context $[16,17]$, and in high-energy femtosecond fiber amplifiers [18].

In this Letter, we demonstrate a FTL picosecond source composed of a seeder system tunable in pulse duration and a hybrid fiber-bulk amplifier able to provide large gain, high pulse energy, and high average power. Pulse-width tunability is obtained by exploiting the spectral compression effect induced by self-phase modulation (SPM) in an optical fiber. The DPA architecture is used to scale the pulse energy beyond the self-focusing threshold both in the fiber amplifier and in the Yb:YAG bulk amplifier. This system has the advantage to be relatively simple compared to already existing sources used for the same applications $[11,19]$. This results in a source capable of delivering $3 \mathrm{ps}, 350 \mu \mathrm{J}$ pulses at a repetition rate of $50 \mathrm{kHz}$, corresponding to $17.5 \mathrm{~W}$ average power. These performances are obtained in a compact and robust setup, and can be easily adjusted in the 3-20 ps range of pulse duration, in 


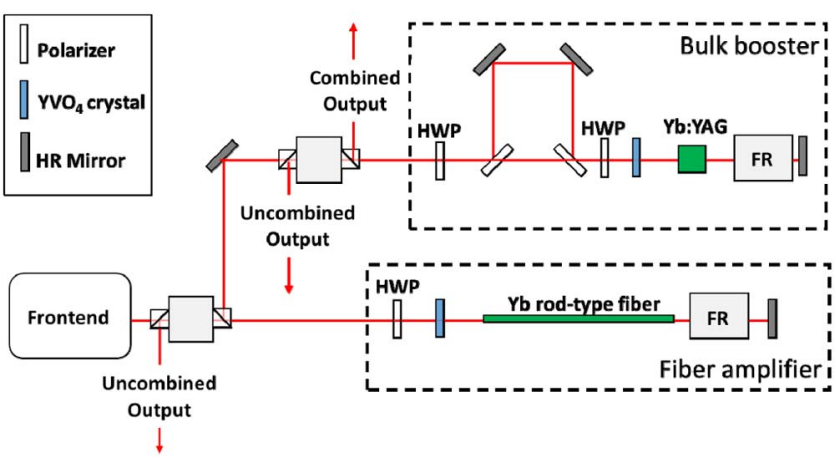

Fig. 1. Schematic laser setup. HWP, half-wave plate; FR, Faraday rotator.

energy $(10-350 \mu \mathrm{J})$, and in average power $(10-50 \mathrm{~W})$, making it a particularly versatile source.

The experimental setup, schematically shown in Fig. 1, consists of a front-end generating tunable-in-duration picosecond pulses followed by a fiber power amplifier and an Yb:YAG booster for the generation of energetic output pulses. The front-end is composed of an Yb:KYW bulk oscillator (Mikan, Amplitude Systemes) operating at $54 \mathrm{MHz}$ repetition rate, and delivering $250 \mathrm{fs}$ pulses centered at $1030 \mathrm{~nm}$ with $1.5 \mathrm{~W}$ average power. Pulses are then temporally stretched to picosecond durations using a $1750 \mathrm{l} / \mathrm{mm}$ grating-based arrangement introducing negative chirp. A fiber-based acoustooptic modulator is used to decrease the repetition rate of the oscillator before amplification in a core-pumped YDFA using a $6 \mu \mathrm{m}$ core and a $2 \mathrm{~m}$ long fiber. The repetition rate of the fiber amplifier is $4 \mathrm{MHz}$. When negatively chirped pulses are subjected to SPM in this amplifier, spectral components at both ends of the spectrum are redistributed toward the central wavelength, leading to a spectral narrowing of the pulses [20]. After a propagation length that depends on the initial chirp and strength of the nonlinearity, FTL pulses can be obtained. By controlling the input chirp of the pulse and gain of the amplifier, FTL pulses with continuously tunable pulse width in the range 3-30 ps are easily generated. Figure 2 shows the oscillator and picosecond pulse spectrum after spectral compression-for initial group delay dispersion of $-0.48 \mathrm{ps}^{2}$ and $-2.25 \mathrm{ps}^{2}-$ corresponding to a pulse duration of 3 ps and 20 ps, respectively. The obtained full width at half-maximum spectral bandwidths are 0.7 and $0.19 \mathrm{~nm}$, respectively, confirming the quasi-FTL nature of these pulses. The typical pulse energy out of this first pulse-shaping amplifier stage is 5-30 nJ.
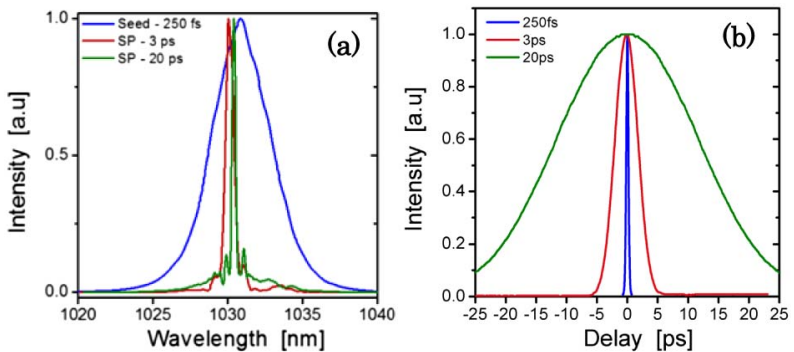

Fig. 2. (a) Initial oscillator spectrum (blue), compressed spectrum for 3 ps (red) and 20 ps (green) pulses. (b) Together with corresponding autocorrelation traces.
Since the generation of FTL picosecond pulses relies on a nonlinear process, a legitimate concern arises over the stability of the narrow spectrum. To investigate this aspect, a long-term measurement of the output spectrum is carried out in the configuration where the amount of SPM is the largest, corresponding to long pulse durations. Figure 3 displays the spectrum of 20 ps pulses and the average power at the output of the first YDFA stage recorded over $9 \mathrm{~h}$, showing power fluctuations of $0.3 \%$ RMS and spectral width fluctuations of 3\% RMS. The use of a highly stable bulk oscillator together with wellintegrated fiber components allows this stability, and residual fluctuations are attributed to beam pointing fluctuations at the input of the fiber subsystem.

Further described experiments are carried out with 3 ps pulses. The first power amplifier is based on a $0.8 \mathrm{~m}$ long $85 / 265 \mu \mathrm{m}$ double-clad distributed-mode filtering rod-type ytterbium-doped fiber pumped with a $50 \mathrm{~W}$ fiber-coupled high-power pump diode system at $976 \mathrm{~nm}$.

It is operated in a double-pass configuration. Despite the very large mode area of the fiber, SPM can induce spectral broadening in this stage depending on the output energy. A convenient way to mitigate this effect consists of partially distributing the spectral compression process in the power amplifier by adjusting the gain of the shaping stage. This allows a maximum pulse energy of $1.5 \mu \mathrm{J}$ for 3 ps pulses, corresponding to $500 \mathrm{~kW}$ peak power, while preserving FTL pulses at the output.

Further energy scaling of this stage is investigated based on the use of theDPA concept. This technique relies on the division of the input pulse into several less energetic temporal replicas [13]. After amplification, these replicas are combined to regenerate a single output pulse. The replicas for this power amplifier stage are generated with a set of three properly oriented yttrium vanadate crystals, which exhibit a large group delay birefringence of $0.7 \mathrm{ps} / \mathrm{mm}$. The length of the smallest crystal is $10 \mathrm{~mm}$ corresponding to a differential group delay of 7 ps, twice the input pulse duration. The two other crystal lengths are 20 and $40 \mathrm{~mm}$ (by combining two $20 \mathrm{~mm}$ crystals), leading to the generation of eight pulse replicas. In each crystal, the incident polarization state is linear and oriented at $45^{\circ}$ of the optical axes, generating at the output two temporally

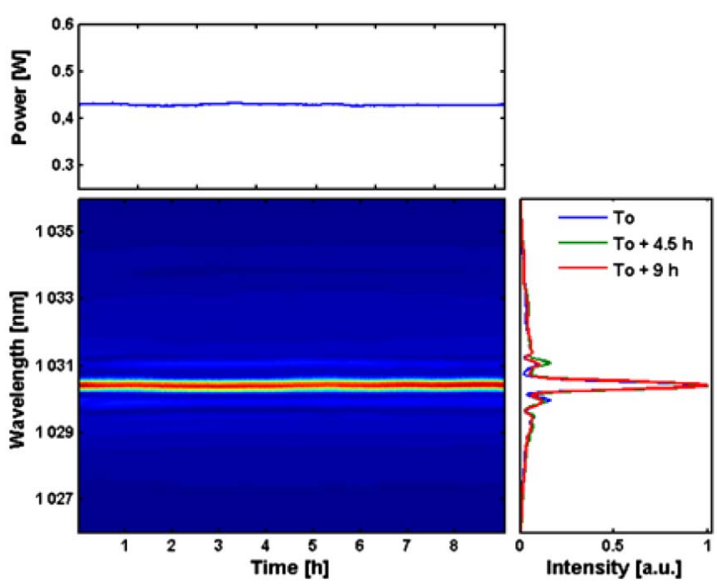

Fig. 3. Long-term stability of the front-end for 20 ps pulse generation. Spectral shape at sampled times (right); average power stability of the oscillator (top). 
separated sets of replicas of equal amplitude and orthogonal polarization. Passive recombination is achieved through a $90^{\circ}$ polarization rotation (using a Faraday rotator), which ensures a complementary propagation path inside the birefringent crystals on the way back, and thus a complete compensation of the previously induced delays. Nonperfect recombination can originate in differential effects among replicas such as a phase shift or gain. In this case, part of the energy of the replicas is directed toward the orthogonal output polarization state, denoted as the uncombined output. Parasitic pulses in the time domain can also appear on the combined output.

Energy scaling results using DPA are shown in Fig. 4. At low energy per replica and for two replicas, the combining efficiency, defined as the combined power divided by total output power, is $99 \%$. This efficiency decreases to $96 \%$ for eight temporal replicas, and we attribute this decrease to slight misalignment of crystal orientations in the dividing/combining stages. At the maximum energy of $1.5 \mu \mathrm{J}$ per replica, the efficiency decreases from $96 \%$ for two replicas down to $88 \%$ for eight replicas. This is attributed to the increased sensitivity of the system to nonperfect replica amplitude equalization that can be turned into phase discrepancies among replicas through accumulated SPM in the amplifier, as detailed in [21]. However, combined output energy of $9.3 \mu \mathrm{J}$ is achieved for 3 ps pulses, corresponding to $3 \mathrm{MW}$ peak power, a record value for a quasi-FTL ps fiber amplifier $[14,15,17]$

To further scale the energy, an additional amplifier based on a $10 \mathrm{~mm}$ long $\mathrm{Yb}: \mathrm{YAG}$ crystal is used. Because of the large gain provided by this bulk booster stage, the DPA divider/combiner is used at the input of the bulk booster. Indeed, the output energy provided by the power fiber amplifier with DPA-using one vanadate crystal-generating two replicas, approximately $3 \mu \mathrm{J}$, is sufficient to ensure efficient energy extraction in the bulk booster, and DPA is needed at this stage to provide energy scaling capabilities. The DPA divider for the bulk Yb:YAG booster generates four replicas to accommodate higher peak power: the first temporal division is based on a combination of thin-film polarizer and free-space delay line $(10 \mathrm{~cm} / 330 \mathrm{ps})$, and the second division is based on a $20 \mathrm{~mm}$ long yttrium vanadate crystal ( $15 \mathrm{ps})$. This allows the final combining process to take place in free space, thereby avoiding self-focusing issues.

The input beam is focused inside the Yb:YAG crystal down to a $400 \mu \mathrm{m}$ waist diameter. The crystal is pumped by a diode system emitting $170 \mathrm{~W}$ of average power at $969 \mathrm{~nm}$, and coupled to a $200 \mu \mathrm{m}, 0.22 \mathrm{NA}$ pump fiber. The output facet of the pump fiber is imaged inside the crystal with a diameter of
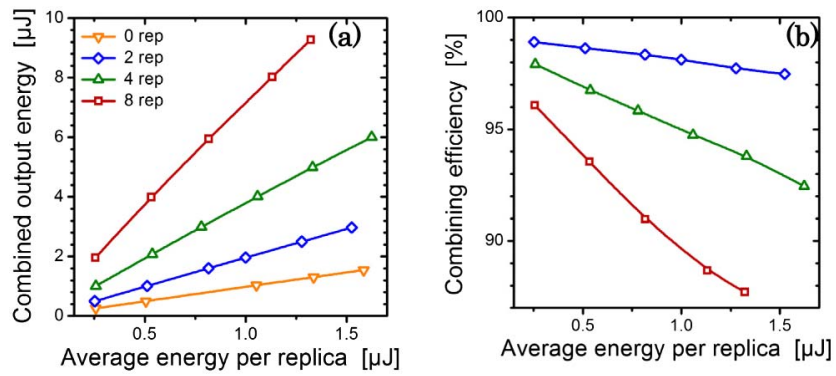

Fig. 4. Evolution of (a) the combined output energy and (b) combining efficiency as a function of energy per replica for different numbers of replicas in the fiber power amplifier.
$500 \mu \mathrm{m}$. Heat removal in the crystal is operated by water cooling of the top and bottom facets of the crystal through a copper mount. The crystal is thermally contacted to the copper mount by a sheet of indium.

We first investigate the output power/energy of the bulk amplifier as a function of repetition rate at a maximum pump power of $170 \mathrm{~W}$, as shown in Fig. 5. An additional acoustooptic modulator located between the rod-type amplifier and the bulk booster allows us to make this systematic study. The output pulse energy increases from $45 \mu \mathrm{J}$ at $1 \mathrm{MHz}$ repetition rate to $350 \mu \mathrm{J}$ at $50 \mathrm{kHz}$, corresponding to average powers of 45 and $18 \mathrm{~W}$, respectively. The $350 \mu \mathrm{J}$ energy corresponds to a peak power of $116 \mathrm{MW}$, and the Kerr focal length associated with this peak power is $<1 \mathrm{~cm}$ in YAG. It is clear that severe self-focusing would occur without using the DPA system. With the DPA activated, the B-integral is estimated around $0.22 \mathrm{rad} / \mathrm{replica}$. In order to decouple, identify, and compensate the thermal lens and the Kerr lens, the setup is aligned in two steps. First, we operate at full pump power but low seed energy to observe the thermal lens only. The backreflecting mirror position is then optimized to compensate it. Afterward, nonlinear effects can be observed by increasing the input signal. The beam propagation changes imparted by the Kerr lens during first and second passes and is more difficult to fully compensate.

The combined power, uncombined power, and combining efficiency are plotted as a function of pump power at $50 \mathrm{kHz}$ repetition rate in Fig. 6. The DPA combining efficiency of the Yb:YAG booster is above $97 \%$ in all cases, because of the low value of B-integral estimated to be $0.3 \mathrm{rad}$ per replica $(350 \mu \mathrm{J}$ output pulse energy). It is also worth noticing that all depolarization effects are also low since they are included in the 3\% combination losses. This illustrates the relevance of DPA for bulk amplifiers pumped with high-brightness diodes, allowing energy-scaling beyond single-pulse self-focusing and optical damage limitations. No noticeable evolution is observed between input and output spectra of the booster amplifier, as shown in Fig. 5. Indeed, spectral evolution essentially occurs during spectral compression, which takes place in the fiber system. The amplified spontaneous emission (ASE) appears to be negligible, as shown in Fig. 5 representing the amplified spectrum in log-scale.

Finally, we investigate spatial properties of the output pulses at $50 \mathrm{kHz}$ repetition rate and maximum energy of $350 \mu \mathrm{J}$. The spatial quality is also pristine, with $M^{2}$ values below 1.15 in both directions and a Gaussian beam profile. For a higher repetition rate, above $40 \mathrm{~W}$ output power, spatial distortions start
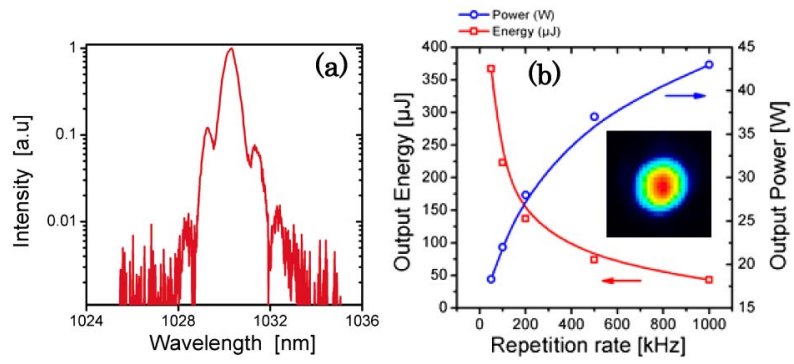

Fig. 5. (a) Output spectrum at $50 \mathrm{kHz}$, (b) output energy and output power as a function of repetition rate at the output of the bulk booster stage for 3 ps pulse duration. Inset: far-field beam profile at $350 \mu \mathrm{J}$. 


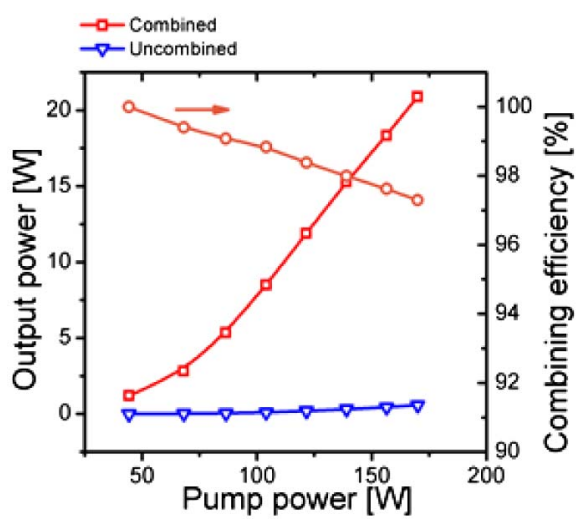

Fig. 6. Combined, uncombined output power, and combining efficiency as a function of pump power at $50 \mathrm{kHz}$ at the output of the bulk booster.

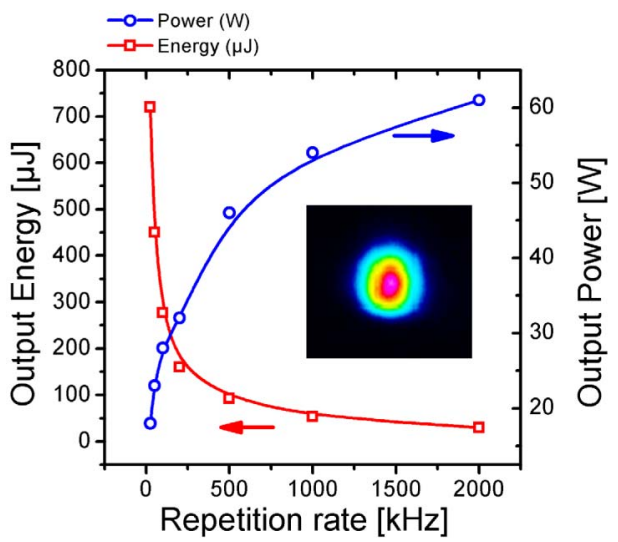

Fig. 7. Output energy and output power as a function of repetition rate at the output of the bulk booster stage for 20 ps pulse duration. Inset: far-field beam profile at $720 \mu \mathrm{J}$.

to appear due to additional heat load induced by strong pump absorption and high gain saturation. The thermal lens limitation is not related to its dioptric power value but to aberrations that cause beam profile degradation.

We also investigated the energy extraction with 20 ps pulses (see Fig. 7). Thanks to the reduced peak intensity we were able to extract $720 \mu \mathrm{J}$ from the Yb:YAG booster without implementing DPA. Damage threshold was reached slightly above $860 \mu \mathrm{J}$ for a single pulse corresponding to a fluence around $500 \mathrm{~mJ} / \mathrm{cm}^{2}$. The use of DPA allows us to operate significantly below the damage threshold.

In conclusion, we report a hybrid high-power versatile source of FTL picosecond pulses based on a rod-type fiber amplifier followed by a bulk Yb:YAG booster. Energy scaling using the DPA technique for the fiber amplifier allows obtaining record performances for this type of system. This method is also advantageously used to scale the energy of the bulk booster, allowing the generation of $350 \mu \mathrm{J}, 3$ ps pulses for a peak power of $116 \mathrm{MW}$. Higher energy has been reached up to $720 \mu \mathrm{J}$ with 20 ps pulse duration for a peak power of $36 \mathrm{MW}$ without any divided pulse scheme. We believe that this type of versatile architecture will allow further energy scaling to the millijoule level mostly by adding division stages, since 32 replica systems have already been demonstrated [16]. It is worth noticing that with such a hybrid configuration based on a fiber-bulk amplifier, we measured in hybrid industrialized systems power fluctuation of $0.3 \% \mathrm{rms}$ and beam pointing stability of $30 \mu \mathrm{rad}$ RMS over $15 \mathrm{~h}$. The bulk booster allows simple energy scaling of over an order of magnitude at the output of a CPA free picosecond fiber system [11] while preserving a very clean and narrow spectrum compatible with highly efficiency frequency conversion.

Funding. French National Research Agency (ANR) (Femtocryble program).

\section{REFERENCES}

1. C.-L. Chang, P. Krogen, K.-H. Hong, L. E. Zapata, J. Moses, A.-L. Calendron, H. Liang, C.-J. Lai, G. J. Stein, P. D. Keathley, G. Laurent, and F. X. Kärtner, Opt. Express 23, 10132 (2015).

2. H. Liang, P. Krogen, R. Grynko, O. Novak, C.-L. Chang, G. J. Stein, D. Weerawarne, B. Shim, F. X. Kärtner, and K.-H. Hong, Opt. Lett. 40, 1069 (2015).

3. S. Prinz, M. Haefner, C. Y. Teisset, R. Bessing, K. Michel, Y. Lee, X. T. Geng, S. Kim, D. E. Kim, T. Metzger, and M. Schultze, Opt. Express 23, 1388 (2015).

4. A. Variola, F. Zomer, E. Bulyak, P. Gladkikh, V. Skomorokhov, T. Omori, and J. Urakawa, Phys. Rev. Spec. Top.-Accel. Beams 14, 031001 (2011).

5. W. S. Graves, J. Bessuille, P. Brown, S. Carbajo, V. Dolgashev, K.-H. Hong, E. Ihloff, B. Khaykovich, H. Lin, K. Murari, E. A. Nanni, G. Resta, S. Tantawi, L. E. Zapata, F. X. Kärtner, and D. E. Moncton, Phys. Rev. Spec. Top.-Accel. Beams 17, 120701 (2014).

6. X. Délen, L. Deyra, A. Benoit, M. Hanna, F. Balembois, B. Cocquelin, D. Sangla, F. Salin, J. Didierjean, and P. Georges, Opt. Lett. 38, 995 (2013).

7. A. Agnesi, L. Carrà, R. Piccoli, F. Pirzio, and G. Reali, Opt. Lett. 37, 3612 (2012).

8. K. Nawata, M. Okida, K. Furuki, K. Miyamoto, and T. Omatsu, Opt. Express 17, 20816 (2009).

9. M. Siebold, M. Hornung, J. Hein, G. Paunescu, R. Sauerbrey, T. Bergmann, and G. Hollemann, Appl. Phys. B 78, 287 (2004).

10. C. Heese, A. E. Oehler, L. Gallmann, and U. Keller, Appl. Phys. B 103, 5 (2011).

11. J. Fu, Q. S. Pang, L. Chang, Z. A. Bai, K. Ai, Y. Chen, M. Chen, G. Li, Y. F. Ma, W. Fan, G. Niu, J. Yu, Y. Liu, X. Zhang, W. Y. Kang, and K. He, Laser Phys. 21, 1042 (2011).

12. T. Metzger, A. Schwarz, C. Y. Teisset, D. Sutter, A. Killi, R. Kienberger, and F. Krausz, Opt. Lett. 34, 2123 (2009).

13. J.-P. Negel, A. Voss, M. A. Ahmed, D. Bauer, D. Sutter, A. Killi, and T. Graf, Opt. Lett. 38, 5442 (2013).

14. J. Limpert, N. Deguil-Robin, I. Manek-Hönninger, F. Salin, T. Schreiber, A. Liem, F. Röser, H. Zellmer, A. Tünnermann, A. Courjaud, C. Hönninger, and E. Mottay, Opt. Lett. 30, 714 (2005).

15. Y. Zaouter, E. Cormier, P. Rigail, C. Hönninger, and E. Mottay, Proc. SPIE 6453, 645300 (2007).

16. S. Zhou, F. W. Wise, and D. G. Ouzounov, Opt. Lett. 32, 871 (2007).

17. L. J. Kong, L. M. Zhao, S. Lefrancois, D. G. Ouzounov, C. X. Yang, and F. W. Wise, Opt. Lett. 37, 253 (2012).

18. F. Guichard, Y. Zaouter, M. Hanna, K.-L. Mai, F. Morin, C. Hönninger, E. Mottay, and P. Georges, Opt. Lett. 40, 89 (2015).

19. J.-P. Negel, A. Loescher, A. Voss, D. Bauer, D. Sutter, A. Killi, M. A. Ahmed, and T. Graf, Opt. Express 23, 21064 (2015).

20. B. R. Washburn, J. A. Buck, and S. E. Ralph, Opt. Lett. 25, 445 (2000).

21. F. Guichard, Y. Zaouter, M. Hanna, F. Morin, C. Hönninger, E. Mottay, F. Druon, and P. Georges, Opt. Lett. 38, 4437 (2013). 